\title{
Acute and long-term relocation of minimal lumen area after bioresorbable scaffold or metallic stent implantation
}

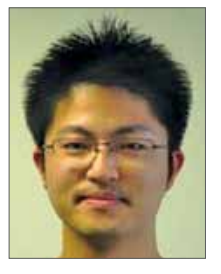

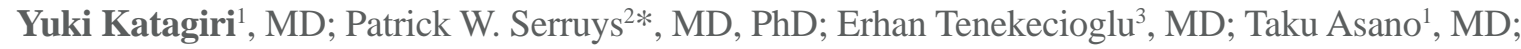
Carlos Collet ${ }^{1}, \mathrm{MD}$; Yosuke Miyazaki ${ }^{3}, \mathrm{MD}$, PhD; Athanasios Katsikis ${ }^{4}, \mathrm{MD}$, PhD; Jan J. Piek ${ }^{1}$, MD, PhD; Joanna J. Wykrzykowska' ${ }^{1}$ MD, PhD; Bernard Chevalier ${ }^{5}$, MD; Gary S. Mintz 6 , MD; Gregg W. Stone ${ }^{6,7}, \mathrm{MD}$; Yoshinobu Onuma ${ }^{3}, \mathrm{MD}, \mathrm{PhD}$

1. Academic Medical Centre, University of Amsterdam, Amsterdam, the Netherlands; 2. NHLI, Imperial College London, London, United Kingdom; 3. Thoraxcenter, Erasmus Medical Center, Rotterdam, the Netherlands; 4. Cardiology Department, 401 General Military Hospital of Athens, Athens, Greece; 5. Institut Jacques Cartier, Massy, France; 6. Cardiovascular Research Foundation, New York, NY, USA; 7. The New York Presbyterian Hospital, Columbia University Medical Center, New York, NY, USA

GUEST EDITOR: Alec Vahanian, MD, PhD; Department of Cardiology, Hôpital Bichat-Claude Bernard, and University Paris VII, Paris, France

This paper also includes supplementary data published online at: https://eurointervention.pcronline.com/doi/10.4244/EIJ-D-18-00422

\begin{abstract}
Aims: The aim of this study was to investigate relocation of minimal lumen area (MLA) after implantation of a bioresorbable scaffold (BRS).

Methods and results: In the ABSORB II randomised trial (BRS vs everolimus-eluting stent [EES]), lesions were investigated by serial intravascular ultrasound pre procedure, post procedure, and at three years. MLA relocation was defined as an axial MLA shift of more than $2.4 \mathrm{~mm}$. MLA relocation from post procedure to three years was observed in $163 / 237(68.8 \%)$ and $75 / 129(58.1 \%)$ of lesions treated by BRS and EES, respectively $(\mathrm{p}=0.041)$. When matching preprocedural MLA site with the same topographical sites post procedure and at three years, BRS showed significant late lumen enlargement and expansive remodelling compensating for significant plaque increase, whereas EES showed significant late lumen narrowing with significant plaque growth not compensated for by expansive remodelling from post procedure to three years. In the multivariate analysis, female gender, previous PCI, BRS implantation, total device length, and maximal pressure (either at device implantation or post-dilatation) were independently associated with MLA relocation from post procedure to three years.
\end{abstract}

Conclusions: MLA relocation from post procedure to three years was more frequent in BRS than EES. Late lumen enlargement and expansive vessel remodelling at the preprocedural MLA site was observed in BRS, but not in EES. 


\section{Abbreviations}

$\begin{array}{ll}\text { BRS } & \text { bioresorbable scaffold } \\ \text { DES } & \text { drug-eluting stent } \\ \text { EES } & \text { everolimus-eluting stent } \\ \text { IVUS } & \text { intravascular ultrasound } \\ \text { MLA } & \text { minimal lumen area } \\ \text { MLD } & \text { minimal lumen diameter } \\ \text { PCI } & \text { percutaneous coronary intervention } \\ \text { QCA } & \text { quantitative coronary angiography }\end{array}$

\section{Introduction}

Late loss, which is the difference between post-procedure and follow-up minimal luminal diameter (MLD) measured by quantitative coronary angiography (QCA), has been one of the most commonly accepted parameters to assess the efficiency of balloon angioplasty, bare metal stents, drug-eluting stents, and bioresorbable scaffolds (BRS). However, late loss is calculated regardless of the respective axial location of the MLDs along the treated area post procedure and at follow-up; therefore, it does not necessarily reflect the actual vessel wall change at the site of the original MLD/MLA.

Intuitively, when we analyse serial investigation of minimal lumen area (MLA) obtained with intravascular ultrasound, we assume that the decrease (or increase) in MLA occurs at the initial location of narrowing post procedure. The statistical reports of serial assessment of MLA post procedure and at follow-up are sometimes misinterpreted, since the statistical evaluation (paired values) suggests that the same longitudinal region of interest or the same cross-section(s) have been compared. Long-term outcome by intravascular ultrasound (IVUS) or angiography of balloon angioplasty, bare metal stents, brachytherapy, and drug-eluting stents has repeatedly indicated that the longitudinal topographical location of the MLA may change from its preprocedural site to its post-procedural site and to its follow-up site. The acute relocation (pre procedure/post procedure) is related to acute mechanical treatment, while the late topographical relocation (post procedure/ follow-up) is a phenomenon more related to the long-term biological reaction of the vessel wall.

Relocation of the MLA after implantation of a BRS has not yet been studied. Therefore, we studied MLA relocation using IVUS as a post hoc study of the ABSORB II trial, which compared the Absorb $^{\mathrm{TM}}$ everolimus-eluting BRS and the XIENCE metallic everolimus-eluting stent (EES) (both Abbott Vascular, Santa Clara, CA, USA) in the context of a randomised trial. The aims of this study were 1) to compare acute and late MLA relocation in BRS with relocation in metallic EES as well as the serial long-term morphometric changes of the initial preprocedural MLA site at three-year follow-up, and 2) to attempt to unravel the main determinants of late relocation phenomenon.

\section{Methods}

\section{STUDY DESIGN AND POPULATION}

The ABSORB II trial was a prospective, single-blind, multicentre clinical trial that randomised patients to percutaneous coronary intervention (PCI) with either BRS or metallic EES in a 2:1 fashion. The trial design, the study devices, and the inclusion and exclusion criteria have been described in detail previously ${ }^{1}$. As mandated by the protocol, all patients underwent documentary greyscale IVUS and backscattered radiofrequency assessment before and after device implantation and at three-year follow-up. The ABSORB II trial was funded by Abbott Vascular.

\section{IVUS IMAGE ACQUISITION AND ANALYSIS}

IVUS data were acquired with a $3.2 \mathrm{Fr}, 45-\mathrm{MHz}$ rotational IVUS catheter (Revolution ${ }^{\circledR} 45 \mathrm{MHz}$; Volcano Corporation, Rancho Cordova, CA, USA) after intracoronary injection of $200 \mu \mathrm{g}$ of nitroglycerine, at a pullback speed of $0.5 \mathrm{~mm} / \mathrm{second}$ and a frame speed of 30 frames/second. All pullbacks were analysed off-line at $1 \mathrm{~mm}$ longitudinal intervals by an independent core laboratory (Cardialysis BV, Rotterdam, the Netherlands) using commercially available software (QIvus version 2.2; Medis, Leiden, the Netherlands).

\section{DEFINITIONS OF IVUS PARAMETERS}

The methods of quantitative IVUS have been published previously ${ }^{2}$. Vessel contour was delineated along the border between the media and the adventitia. Lumen contour was delineated along the border between flowing blood and the vessel wall. In case of malapposition, the lumen border was assessed behind the struts. In order to compare the two devices, and considering the difficulty of measuring the neointima in the biodegraded scaffold at three years, the intrascaffold/stent neointima was included in the metric "plaque/media = vessel area - lumen area". Plaque area increase or "plaque growth" is a metric name used to describe, in a combined fashion, tissue growth behind polymeric or metallic struts, and tissue growth intrascaffold or intra-stent ${ }^{3,4}$. The reference segments after device implantation were the $5 \mathrm{~mm}$ segments proximal and distal to the device.

Definitions of expected balloon-artery ratio, expansion index, asymmetry index, eccentricity index as well as details of the analysis method in preprocedural IVUS-VH are described in Supplementary Appendix 1.

\section{DEFINITION OF RELOCATION OF MLA}

We defined the position of the MLA in the scaffold/stent, either pre procedure, post procedure or at follow-up, as the distance from the distal edge of the scaffold/stent to the MLA site. Previously, ArbabZadeh et al reported that the average IVUS probe motion during the cardiac cycle was $2.43 \pm 1.42 \mathrm{~mm}$ as assessed by cineangiography ${ }^{5}$. Accordingly, relocation was considered as a present phenomenon whenever longitudinal MLA position changed by more than $2.4 \mathrm{~mm}$, either proximally or distally. Acute relocation was defined as relocation from pre procedure to post procedure; late relocation was defined as relocation from post procedure to follow-up (Figure 1).

\section{MATCHING MLA LOCATION WITH IVUS AT DIFFERENT TIME POINTS (PRE PROCEDURE, POST PROCEDURE, FOLLOW-UP)}

After identifying the frame of the MLA site, matching with IVUS at a different time point was performed by colocalising common 
landmarks ${ }^{6}$ (Figure 1). The preprocedural MLA cross-section was matched with the corresponding cross-section post procedure and at three years. The post-procedural MLA cross-section was matched with the corresponding cross-section pre procedure and at three years. The three-year MLA cross-section was matched with the corresponding cross-section pre procedure and post procedure. In addition, the post-procedural MLA cross-section was matched with the preprocedural corresponding site of IVUS-VH for plaque compositional analysis.

\section{STATISTICAL ANALYSIS}

The method of statistical analysis is described in Supplementary Appendix 1.

\section{Results}

\section{BASELINE CHARACTERISTICS}

In the ABSORB II trial, out of the 501 patients enrolled, a complete set of IVUS pre procedure, post procedure, and at three years

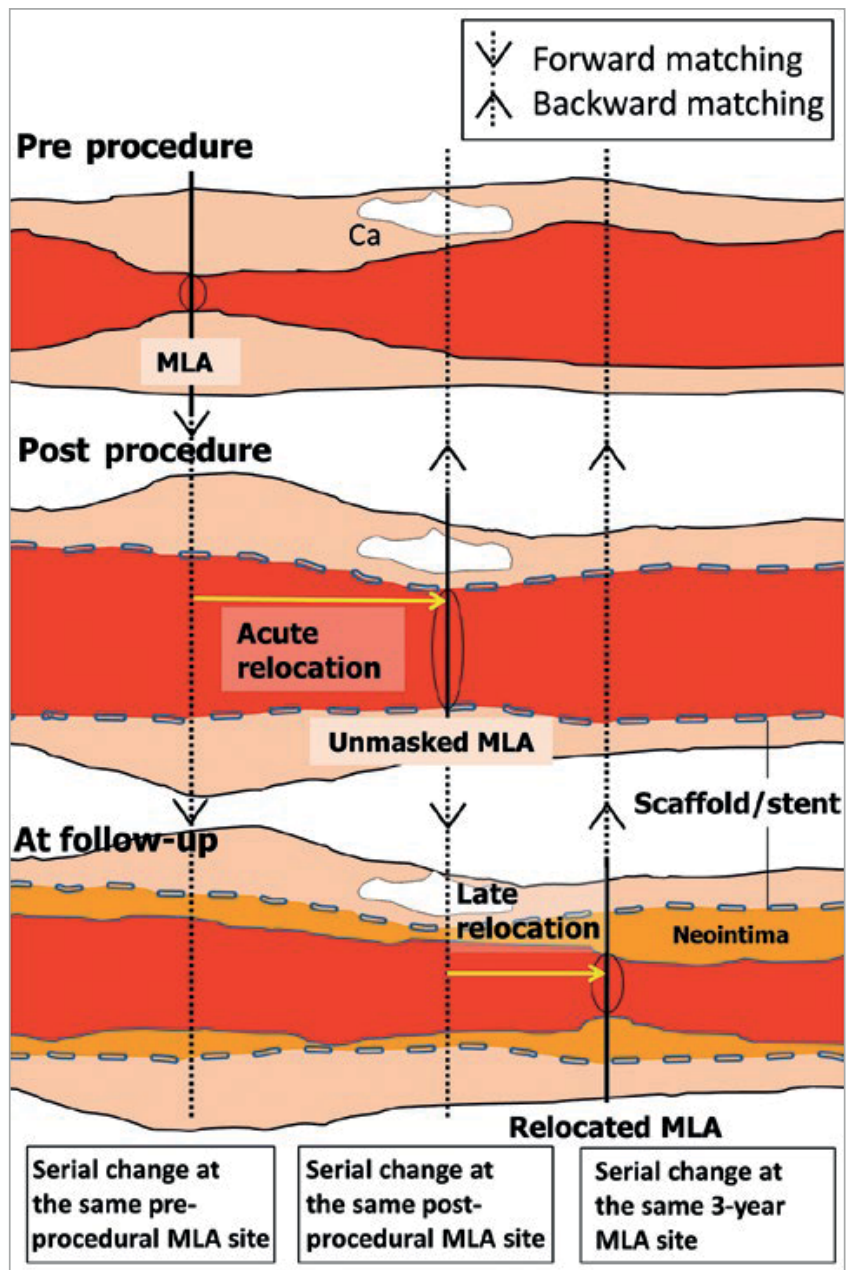

Figure 1. Matching the MLA site on IVUS at various time points. Pre-procedure, post-procedure and follow-up MLA cross-sectional images were colocalised prospectively $(\downarrow)$ and retrospectively $(\uparrow)$ and serially analysed for assessment of lumen and vessel area. Ca: calcification; MLA: minimal lumen area was available in 237 lesions (224 patients) in the BRS arm and 129 lesions (120 patients) in the EES arm (Figure 2). Baseline clinical and lesion characteristics in those patients/lesions were well balanced between both arms (Supplementary Table 1). In terms of procedural characteristics, maximal pressure during device implantation or post-dilatation, as well as the nominal diameter of the post-dilatation balloon, were significantly higher in the EES arm than in the BRS arm.

\section{INCIDENCE OF ACUTE AND LATE RELOCATION}

In 366 lesions with a complete set of IVUS pre procedure, post procedure, and at three-year follow-up, 166/366 (45.4\%) lesions did not have acute relocation (residual MLA) (Figure 3). In these lesions without acute relocation, MLA in 59/166 (35.5\%) lesions stayed at the same site at pre procedure, post procedure, and threeyear follow-up, while 107/166 (64.5\%) lesions showed late relocation at three years.

In lesions with acute relocation (200/366), 69/200 (34.5\%) so-called "unmasked" MLA lesions remained at three years the MLA at the same site, whereas at follow-up a de novo MLA superseded the "unmasked" post-procedural MLA in 131/200 (65.5\%) lesions.

Rates of late relocation in lesions without acute relocation were similar between the two arms $(65.8 \%$ vs $61.8 \%, \mathrm{p}=0.617)$, whereas, in lesions with acute relocation, late relocation was significantly more frequent in the BRS arm than in the EES arm (71.4\% vs $55.4 \%, \mathrm{p}=0.021$ ). (Figure 3 ).

Overall, the proportion of lesions with late MLA relocation was greater in the BRS arm than in the EES arm (163/237 [68.8\%] vs 75/129 [58.1\%], p=0.041) (Supplementary Figure 1).

\section{COLOCALISED CHANGES OF THE INDEX PREPROCEDURAL MLA AT POST PROCEDURE AND AT FOLLOW-UP}

Serial changes of lumen, plaque, and vessel area of the index preprocedural MLA site are shown in Figure 4. When all lesions were combined regardless of relocation status, BRS showed significant late lumen enlargement with expansive remodelling overcompensating for significant "plaque growth", whereas EES showed significant late lumen narrowing with significant expansive remodelling unable to compensate for a significant "plaque growth" at the preprocedural MLA site from post procedure to three-year follow-up (Figure 4A).

In lesions without relocation (no acute or late relocation), no significant change in lumen area or vessel area was observed in both BRS and EES arms from post procedure to three years (A in Figure 3, Figure 4B).

At the preprocedural MLA site in lesions without acute but with late relocation, BRS showed significant late lumen enlargement with significant expansive remodelling overcompensating for a significant "plaque growth" from post procedure to three years. On the other hand, EES did not show any significant change in lumen, plaque, or vessel area from post procedure to three years (B in Figure 3, Figure 4C). 


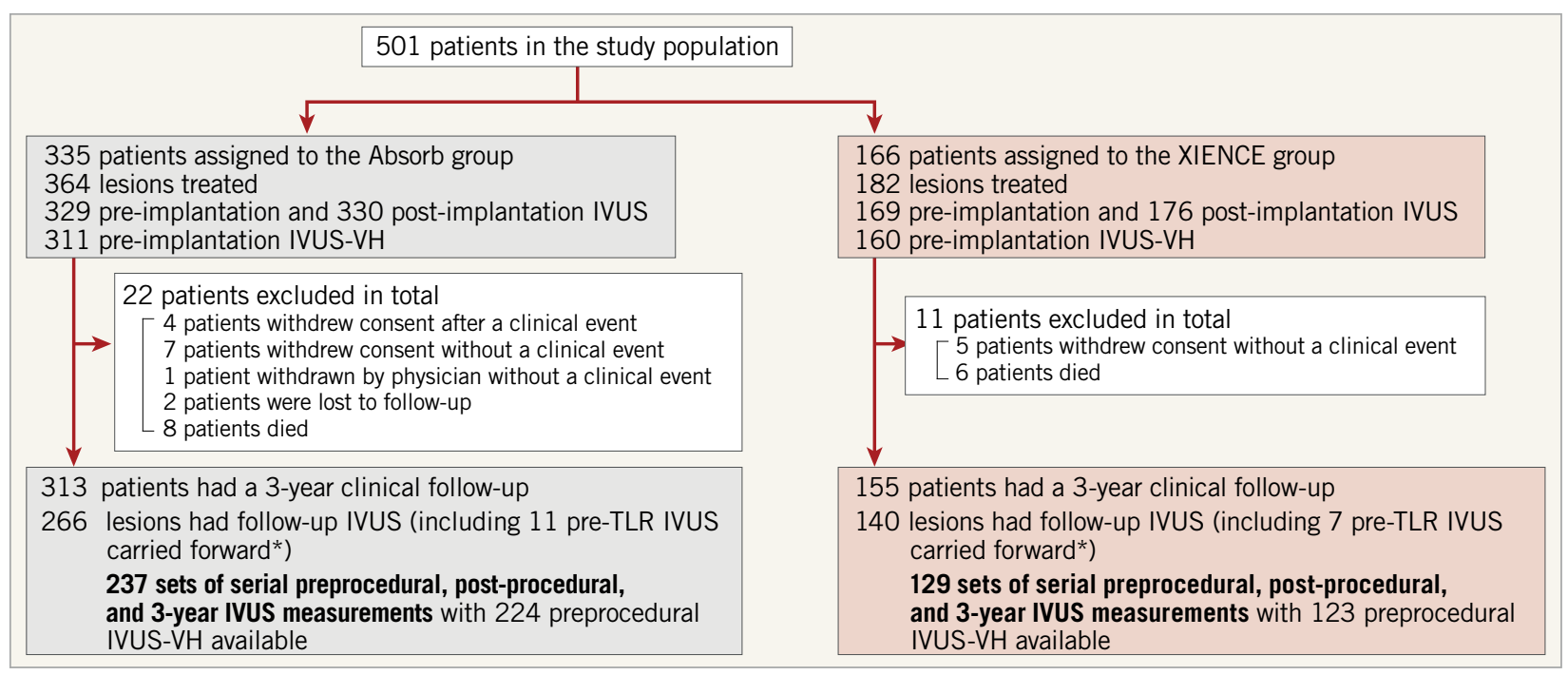

Figure 2. Study flow chart. *In case of TLR, the results of pre-TLR IVUS were carried forward to $3 Y$ for statistical purpose.

IVUS: intravascular ultrasound; MLA: minimal lumen area; TLR: target lesion revascularisation; VH: virtual histology

Initial preprocedural MLA, in lesions with acute MLA relocation but without late relocation, showed a non-significant increase in lumen and plaque area with significant expansive remodelling in BRS; EES showed stable lumen area with significant "plaque growth" compensated for by significant expansive remodelling from post procedure to three years (C in Figure 3, Figure 4D).

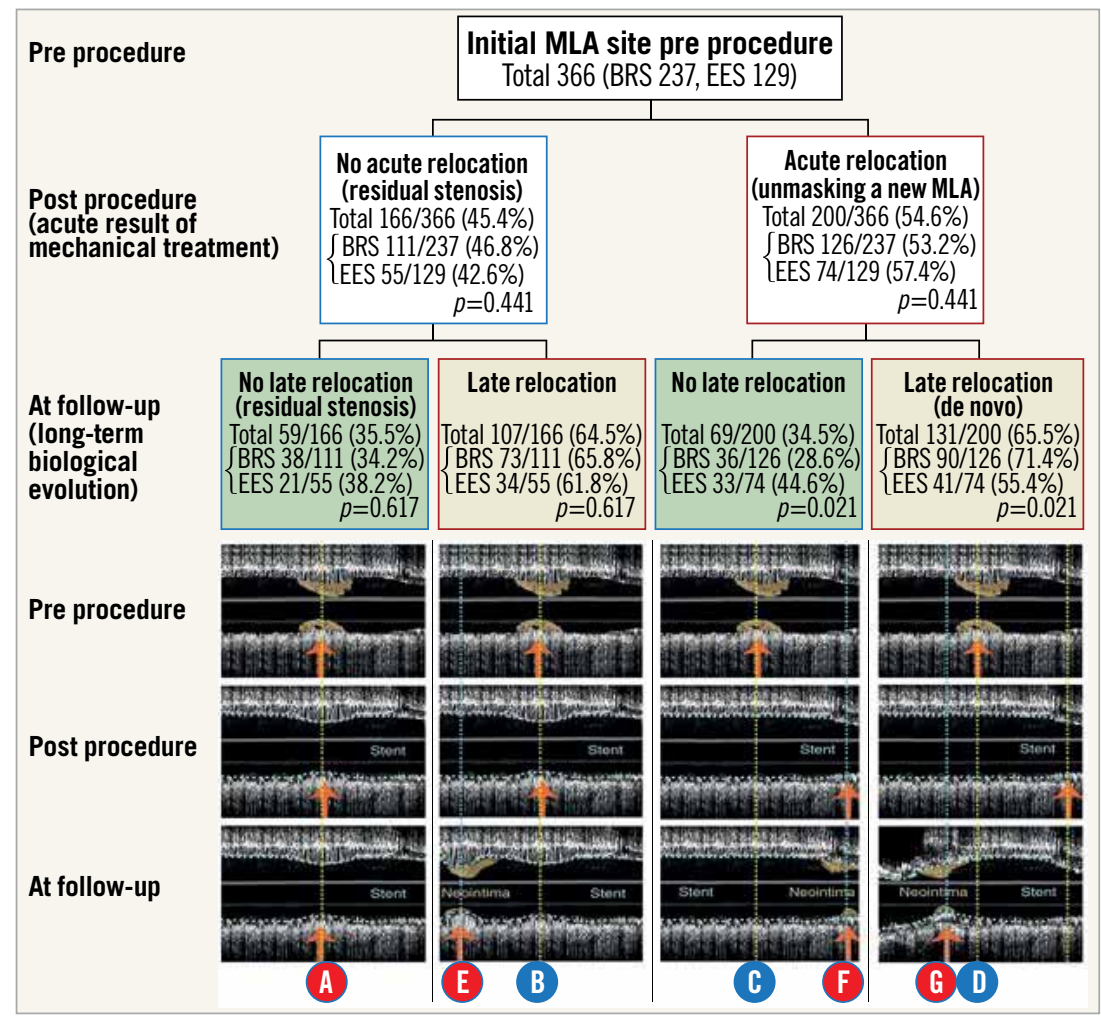

Figure 3. Serial change of longitudinal position of MLA (truly serial IVUS pre procedure, post procedure, and at three-year follow-up: $n=366$ lesions). Acute or late MLA relocation is defined as either a proximal or distal shift greater than $2.4 \mathrm{~mm}$ from pre procedure to post procedure or post procedure to follow-up. Yellow dotted lines indicate a cross-section matched post procedure or at follow-up with the initial site of the preprocedural MLA. Line A: in lesions without any acute or late relocation; line B: in lesions without acute but with late relocation; line C: in lesions with acute but without late relocation; and line D: in lesions with acute and late relocation. Blue dotted line indicates the MLA cross-section at follow-up "back-matched" with pre-procedure or post-procedure cross-sections. Line E: in lesions without acute but with late relocation; line F: in lesions with acute but without late relocation; line G: in lesions with acute and late relocation. 


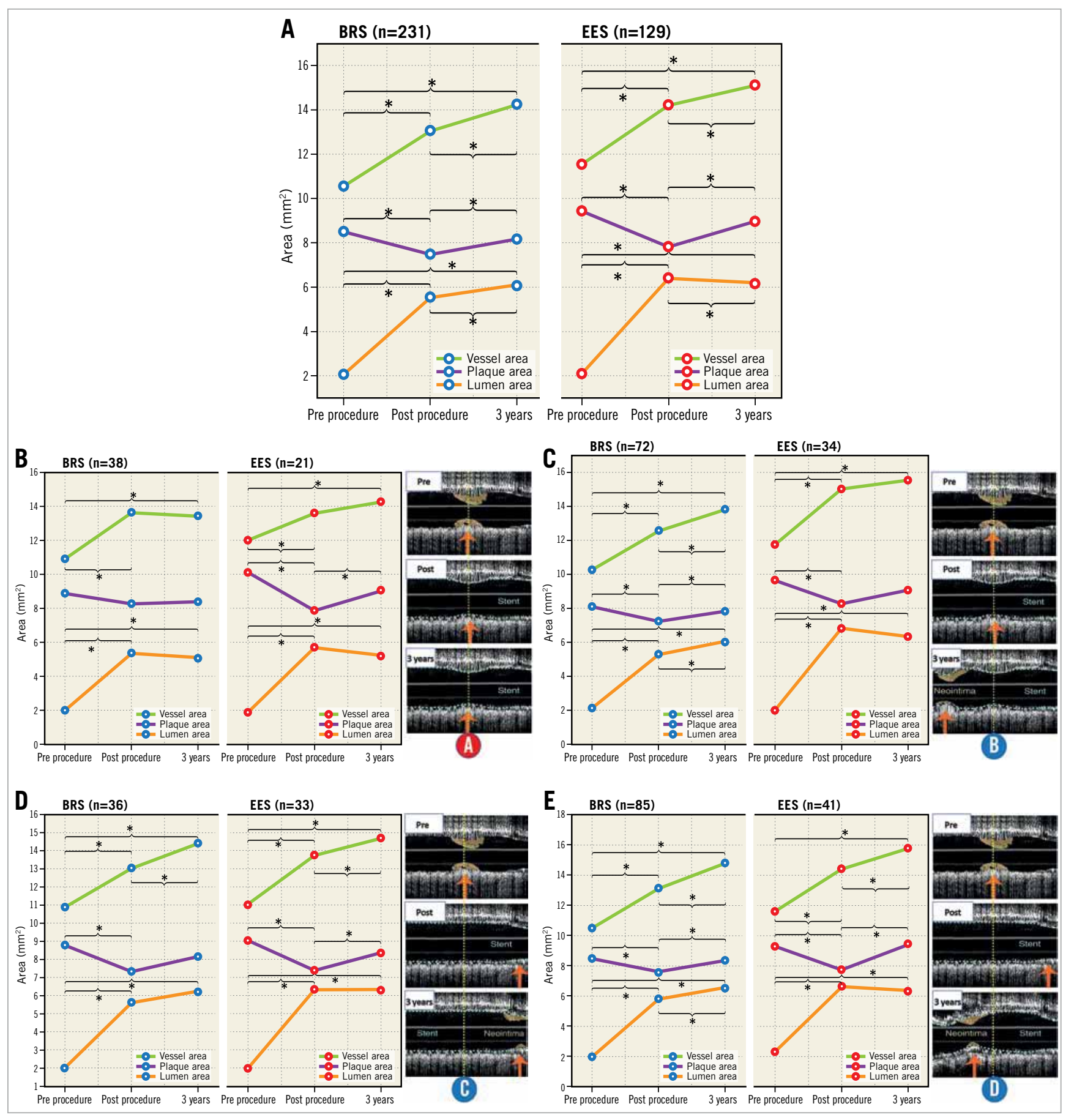

Figure 4. Serial changes (post procedure, three years) of lumen, plaque, and vessel area at the initial site of preprocedural MLA. A) Serial changes at the preprocedural MLA site regardless of relocation status. Aggregated data from lines A, B, C, and D in Figure 3. B) Serial changes at the preprocedural MLA site without any acute or late relocation (the same MLA site pre procedure, post procedure, at three years). Line A in Figure 3. C) At the site of preprocedural MLA in lesions without acute relocation but with late relocation. Line B in Figure 3. D) At the site of preprocedural MLA with acute relocation but without late relocation. Line C in Figure 3. E) At the site of preprocedural MLA with acute and late relocation. Line D in Figure 3. All serial changes except plaque area in BRS in panel B were significant in repeated measures ANOVA. p-values for pairwise comparisons were adjusted by Bonferroni correction. *p<0.05. BRS: bioresorbable scaffold; EES; everolimuseluting stent

In lesions with both acute and late relocation, BRS showed significant late lumen enlargement with expansive remodelling overcompensating for a significant "plaque growth"; EES showed no significant change in lumen area with significant "plaque growth" compensated for by expansive remodelling from post procedure to three years ( $D$ in Figure 3, Figure 4E). 
BACKWARD MATCHING PRE AND POST PROCEDURE OF THE THREE-YEAR MLA

When lesions with any acute or late MLA relocation (E, F, and G in Figure 3) were combined, both BRS and EES showed significant lumen reduction due to plaque increase and constrictive remodelling at the three-year MLA site from post procedure to three years (Supplementary Figure 2). The analyses in subgroups are included in Supplementary Appendix 2.

\section{MULTIVARIATE ANALYSIS FOR PREDICTORS OF LATE MLA RELOCATION}

Univariate analyses for predicting late MLA relocation at three years were performed, with the result tabulated in Supplementary Table 2. Subsequent multivariate analysis retained the following in the model as independent predictors of late MLA relocation: female gender, previous PCI, BRS implantation, total device length, and maximal pressure either at device implantation or at post-dilatation (Table 1).

Table 1. Multivariate analysis predicting MLA relocation from post procedure to 3 years.

\begin{tabular}{|l|c|c|}
\hline & Overall OR [95\% Cl] & $\boldsymbol{p}$-value \\
\hline Female & $2.05[1.16,3.63]$ & 0.014 \\
\hline Previous PCI & $1.71[1.05,2.79]$ & 0.031 \\
\hline BRS implantation & $1.68[1.02,2.78]$ & 0.043 \\
\hline Length of implanted device (per mm) & $1.04[1.01,1.07]$ & 0.006 \\
\hline $\begin{array}{l}\text { Maximal pressure either at device } \\
\text { implantation or at post-dilatation } \\
\text { (per atm) }\end{array}$ & $1.08[1.00,1.16]$ & 0.042 \\
\hline Asymmetry index $>0.3$ & $0.79[0.46,1.36]$ & 0.398 \\
\hline Minimum eccentricity index $<0.7$ & $1.32[0.68,2.59]$ & 0.415 \\
\hline Mean LDL (per mmol/L) & $1.23[0.85,1.78]$ & 0.267 \\
\hline
\end{tabular}

LDL: low-density lipoprotein; MLA: minimal lumen area; OR: odds ratio; $\mathrm{PCl}$ : percutaneous coronary intervention

\section{Discussion \\ MAIN FINDINGS}

The main findings of this study are the following. 1) Late MLA relocation was more frequent in lesions treated with BRS than in those treated with EES. 2) At the original site of MLA, late lumen enlargement with expansive remodelling overcompensating for "plaque growth" occurred in the BRS arm, whereas in the EES arm significant lumen reduction due to significant plaque growth not compensated for by expansive remodelling was observed over three years. 3) The relocated three-year MLA site was characterised by lumen area reduction due to plaque progression in combination with constrictive remodelling in both arms. 4) Female gender, previous PCI, BRS implantation, total device length, and maximal pressure during the procedure were independent predictors of late MLA relocation.

The current study is not limited to a description of MLA relocation, but also shows the physiopathological impact of pressure applied to the luminal wall in the treated segment. On the one hand, high pressure during the procedure may promote strut embedment and expansive remodelling, while it can promote neointimal hyperplasia by inflammatory reaction ${ }^{7,8}$. On the other hand, low pressure may result in poor embedment and excessive strut protrusion into the lumen and causes an area of low shear stress resulting in an early phase, fibrin deposition, thrombosis and exuberant neointimal hyperplasia and in a late phase neoatherosclerosis 9 . In a previous report by Stone et $\mathrm{al}^{10}$, optimal predilatation (with a balloon to QCA-RVD ratio $\geq 1: 1$ ) was associated with greater one-year rates of target lesion failure (TLF), while optimal post-dilation (with a non-compliant balloon at $\geq 18$ atm and with a nominal diameter larger than the nominal scaffold diameter, but not $>0.5 \mathrm{~mm}$ larger) was associated with lower TLF rates between one and three years after BRS implantation. In their report, the pathophysiological reason why "optimal predilatation" and "optimal post-dilatation" work oppositely was unclear. Importantly, in the present study, we identified maximal pressure during the procedure as an independent determinant of late MLA relocation, suggesting its physiological impact on de novo stenosis at follow-up. However, we could not find statistical significance in relationships between MLA relocation and clinical outcomes due to the limited number of events (Supplementary Table 3).

\section{COMPARISON WITH PREVIOUS LITERATURE}

Sabaté et al reported that late MLD relocation was observed in $78.5 \%$ of lesions treated with brachytherapy and only in $26.3 \%$ of lesions treated with balloon angioplasty $(\mathrm{p}<0.0001)^{11}$. Costa et al reported that MLD relocation on angiography occurred in $42.8 \%$ with BMS and 33.7-36.4\% with DES at nine-month follow-up ${ }^{12}$. Our results show a rate of late MLA relocation on IVUS of $59.6 \%$ with metallic EES, which is higher than that reported by Costa et al. The longer follow-up period of our population (three years vs nine months) might have resulted in a different impact of neointimal growth on MLA relocation. On the other hand, the rate of MLA relocation with BRS in the present study was higher than in lesions treated with balloon angioplasty in the work previously reported by Sabaté et al.

The Absorb bioresorbable scaffold is considered to lose its mechanical support at six to 12 months, with a complete polymer resorption at three to four years ${ }^{13}$. However, future research is needed to understand how the scaffold influences the change in lumen configuration between loss of mechanical support and complete absorption.

\section{PREDICTORS OF LATE MLA RELOCATION}

BRS implantation, female gender, balloon-artery ratio, expansion index, previous history of PCI, and low-density lipoprotein (LDL) were independent determinants of expansive remodelling in our previous report based on device-level analysis ${ }^{14}$. Most of these predictors of device-level expansive remodelling overlap with the predictors of late MLA relocation in the present cross-sectional level analysis. Indeed, univariate logistic regression analysis shows that 
expansive remodelling (defined as mean vessel area increase $>12 \%$ ) has an odds ratio of 1.98 (95\% confidence interval: 1.14-3.44, $\mathrm{p}=0.015$ ) predicting late MLA relocation. Although we could not include expansive remodelling (yes/no) in the multivariate model considering multicollinearity with other factors, it is quite possible that expansive remodelling is related to late MLA relocation.

Female gender appears to be an independent predictor of late MLA relocation. Previously, Trabattoni et al reported that female gender was more frequently associated with in-stent restenosis as compared to male gender ${ }^{15}$. Moreover, females had more diffuse in-stent restenosis (ISR) (71.8\%) than males (40.3\%). In lesions with diffuse restenosis, MLA relocation may occur more easily.

In the present study, previous PCI (early onset of coronary artery disease) was an independent predictor of late MLA relocation. Although prior PCI has been identified as a predictor of target lesion revascularisation ${ }^{16}$, the impact on MLA relocation has not been reported.

Total device length is associated with late MLA relocation. As the device length increases, it is reasonable to postulate that a topographical restenotic process in a locus other than the original MLA will be more likely.

After adjusting for other patient characteristics and procedural factors, BRS implantation is still an independent predictor of late MLA relocation. The vessel treated with BRS is free from caging when the mechanical integrity of the scaffold is lost. It has been shown that late loss is higher in BRS than in $\mathrm{EES}^{1}$, whereas lesions treated with BRS have more potential for vessel remodelling as compared to metallic stents ${ }^{14}$. However, the site of remodelling or lumen reduction may be difficult to explain solely by the factors discussed above.

Previous literature has shown that higher pressure may trigger both neointimal hyperplasia and vessel remodelling ${ }^{7,8}$. In the current study, maximal pressure during the procedure was an independent determinant of late MLA relocation. Serial and matched change of initial preprocedural MLA site showed late lumen enlargement with expansive remodelling in BRS, while late lumen reduction was observed in EES so that lumen area at follow-up was almost identical $\left(6 \mathrm{~mm}^{2}\right)$ in both arms (Figure 4A). In case of acute or late relocation, both arms exhibited late lumen reduction due to constrictive remodelling and "plaque growth" (Supplementary Figure 2A). High pressure at the site of the index MLA has a beneficial effect in the BRS arm long term, while high pressure may trigger in both arms relocation that is associated with long-term deterioration of the lumen at sites other than the index stenotic site. In other words, high-pressure implantation or post-dilatation might be viewed as a double-edged sword ${ }^{10}$. These observations are hypothesis-generating but would suggest either the use of highly pressurised non-compliant balloon delivery with an oversized mid part of the balloon or the use for post-dilatation of a short, oversized balloon centred on the minimal lumen area (both not $>0.5 \mathrm{~mm}$ larger than the nominal diameter of the scaffold to avoid fractures in the BRS) (Figure 5).

\section{Post-dilatation by conventional Post stenting non-compliant balloon}

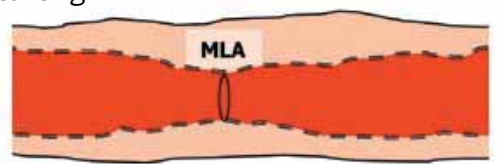

Post-dilatation B/A ratio 1.25
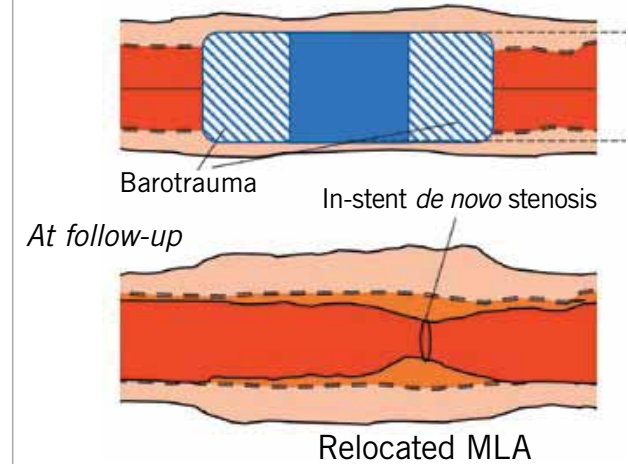

Post-dilatation by balloon with oversized mid part

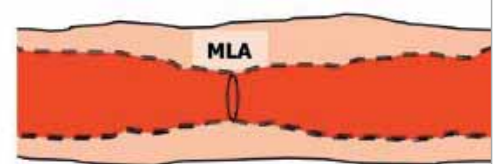

Localised B/A ratio 1.25

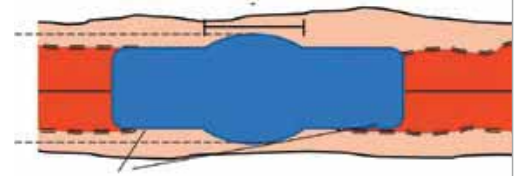

No barotrauma

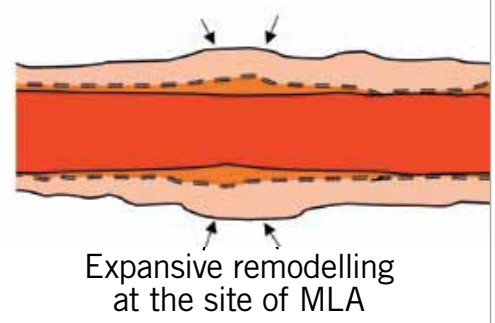

Figure 5. Difference between pressure applied along the balloon length and to a localised region. Maximal pressure either during device implantation or at the time of post-dilatation is one of the independent determinants of late MLA relocation as well as BRS implantation. High pressure at the site of the index MLA has a beneficial effect, while at sites other than the index stenotic site high pressure may trigger MLA relocation that is associated with long-term deterioration of the lumen. The observation suggests either the use of highly pressurised noncompliant balloon delivery with an oversized mid part of the balloon or the use for post-dilatation of a short, oversized balloon centred on the minimal lumen area. B/A ratio: balloon-artery ratio; MLA: minimal lumen area 
Although none of the geometric parameters (i.e., asymmetry index or eccentricity index) was identified as an independent factor predicting late MLA relocation in this study, luminal configuration affects shear stress, which is considered to impact on neointimal formation ${ }^{9}$. To understand the underlying mechanism of late MLA relocation fully, the influence of shear stress should be taken into account and investigated.

\section{Study limitations}

Matching analysis inherently suffered from longitudinal error due to cardiac motion. In a study in saphenous vein grafts after stent implantation, QCA-derived MLD position and IVUS-derived MLD failed to correlate ${ }^{17}$, which may be accounted for by the longitudinal inaccuracy of QCA due to vessel foreshortening, whereas cross-sectional and longitudinal IVUS measurement is not affected by 2D geometric limitation. Optical coherence tomography (OCT) was not available in ABSORB II. Although OCT has better longitudinal accuracy with faster pullback speed, it still suffers from longitudinal error ${ }^{18}$. Due to bioresorption of the BRS up to three years, the core lab could not measure the scaffold area at three years in 3,737 frames among 6,531 frames analysed in the BRS arm. Therefore, a separate analysis of neointima and plaque behind struts could not be performed and the analysis focused on total plaque area.

\section{Conclusions}

In the ABSORB II trial, late MLA relocation was more frequent in lesions treated with BRS than in those treated with EES. Late lumen enlargement and expansive vessel remodelling at the site of the initial preprocedural MLA was observed in BRS, but not in EES. At the same time, high pressure may trigger relocation associated with long-term lumen narrowing and constrictive remodelling at sites other than the index stenotic site. The implantation technique and the future design of balloon technology may impact on the long-term outcome of stenting and scaffolding but warrant future prospective investigation.

\section{Impact on daily practice}

Coronary lesions treated with BRS more frequently exhibit MLA relocation from post procedure to follow-up than those treated with EES. Late lumen enlargement and expansive vessel remodelling at the site of initial preprocedural MLA was observed in BRS but not in EES. Considering that maximal pressure during the procedure is one of the identified independent predictors of MLA relocation from post procedure to followup, high pressure might not be applicable consistently along the device segment but should be considered to be applied locally.

\section{Guest Editor}

This paper was guest edited by Alec Vahanian, MD, PhD; Department of Cardiology, Hôpital Bichat-Claude Bernard, and University Paris VII, Paris, France.

\section{Funding}

This study was funded by Abbott Vascular.

\section{Conflict of interest statement}

P.W. Serruys is a member of the Advisory Board for Abbott Vascular. B. Chevalier is a consultant for Abbott Vascular. Y. Onuma is a member of the Advisory Board for Abbott Vascular and has received speaker honoraria from Terumo. The other authors have no conflicts of interest to declare. The Guest Editor is a consultant for Edwards Lifesciences.

\section{References}

1. Serruys PW, Chevalier B, Sotomi Y, Cequier A, Carrie D, Piek JJ, Van Boven AJ, Dominici M, Dudek D, McClean D, Helqvist S, Haude M, Reith S, de Sousa Almeida M, Campo G, Iniguez A, Sabate M, Windecker S, Onuma Y. Comparison of an everolimus-eluting bioresorbable scaffold with an everolimus-eluting metallic stent for the treatment of coronary artery stenosis (ABSORB II): a 3 year, randomised, controlled, single-blind, multicentre clinical trial. Lancet. 2016;388:2479-91.

2. Mintz GS, Nissen SE, Anderson WD, Bailey SR, Erbel R, Fitzgerald PJ, Pinto FJ, Rosenfield K, Siegel RJ, Tuzcu EM, Yock PG. American College of Cardiology Clinical Expert Consensus Document on Standards for Acquisition, Measurement and Reporting of Intravascular Ultrasound Studies (IVUS). A report of the American College of Cardiology Task Force on Clinical Expert Consensus Documents. J Am Coll Cardiol. 2001;37:1478-92.

3. Brugaletta S, Gomez-Lara J, Garcia-Garcia HM, Heo JH, Farooq V, van Geuns RJ, Chevalier B, Windecker S, McClean D, Thuesen L, Whitbourn R, Meredith I, Dorange C, Veldhof S, Rapoza R, Ormiston JA, Serruys PW. Analysis of 1 year virtual histology changes in coronary plaque located behind the struts of the everolimus eluting bioresorbable vascular scaffold. Int $J$ Cardiovasc Imaging. 2012;28:1307-14.

4. Zeng Y, Cavalcante R, Tenekecioglu E, Suwannasom P, Sotomi Y, Collet C, Abdelghani M, Jonker H, Digne F, Horstkotte D, Zehender M, Indolfi C, Saia F, Fiorilli R, Chevalier B, Bolognese L, Goicolea J, Nie S, Onuma Y, Serruys PW; investigators of Absorb II study. Comparative assessment of "plaque/media" change on three modalities of IVUS immediately after implantation of either everolimus-eluting bioresorbable vascular scaffold or everolimus-eluting metallic stent in Absorb II study. Int $J$ Cardiovasc Imaging. 2017;33:441-9.

5. Arbab-Zadeh A, DeMaria AN, Penny WF, Russo RJ, Kimura BJ, Bhargava V. Axial movement of the intravascular ultrasound probe during the cardiac cycle: implications for three-dimensional reconstruction and measurements of coronary dimensions. Am Heart J. 1999;138:865-72.

6. Sotomi Y, Ishibashi Y, Suwannasom P, Nakatani S, Cho YK, Grundeken MJ, Zeng Y, Tateishi H, Smits PC, Barragan P, Kornowski R, Gershlick AH, Windecker S, van Geuns RJ, Bartorelli AL, de Winter RJ, Tijssen J, Serruys PW, Onuma Y. Acute Gain in Minimal Lumen Area Following Implantation of Everolimus-Eluting ABSORB Biodegradable Vascular Scaffolds or Xience Metallic Stents: Intravascular Ultrasound Assessment From the ABSORB II Trial. JACC Cardiovasc Interv. 2016;9:1216-27.

7. Schwartz RS, Huber KC, Murphy JG, Edwards WD, Camrud AR, Vlietstra RE, Holmes DR. Restenosis and the proportional neointimal response to coronary artery injury: results in a porcine model. J Am Coll Cardiol. 1992;19:267-74.

8. Gunn J, Arnold N, Chan KH, Shepherd L, Cumberland DC, Crossman DC. Coronary artery stretch versus deep injury in the development of in-stent neointima. Heart. 2002;88:401-5.

9. Koskinas KC, Chatzizisis YS, Antoniadis AP, Giannoglou GD. Role of endothelial shear stress in stent restenosis and thrombosis: pathophysiologic 
mechanisms and implications for clinical translation. J Am Coll Cardiol. 2012;59:1337-49.

10. Stone GW, Abizaid A, Onuma Y, Seth A, Gao R, Ormiston J, Kimura T, Chevalier B, Ben-Yehuda O, Dressler O, McAndrew T, Ellis SG, Kereiakes DJ, Serruys PW. Effect of Technique on Outcomes Following Bioresorbable Vascular Scaffold Implantation: Analysis From the ABSORB Trials. J Am Coll Cardiol. 2017;70:2863-74.

11. Sabaté M, Costa MA, Kozuma K, Kay IP, van der Wiel CJ, Verin V, Wijns W, Serruys PW. Methodological and clinical implications of the relocation of the minimal luminal diameter after intracoronary radiation therapy. Dose Finding Study Group. J Am Coll Cardiol. 2000;36:1536-41.

12. Costa MA, Sabaté M, Angiolillo DJ, Hu P, Jimenez-Quevedo P, Corros C, Alfonso F, Hernandez-Antolin R, Macaya C, Bass TA. Relocation of minimal luminal diameter after bare metal and drug-eluting stent implantation: incidence and impact on angiographic late loss. Catheter Cardiovasc Interv. 2007;69:181-8.

13. Otsuka F, Pacheco E, Perkins LE, Lane JP, Wang Q, Kamberi M, Frie M, Wang J, Sakakura K, Yahagi K, Ladich E, Rapoza RJ, Kolodgie FD, Virmani R. Long-term safety of an everolimus-eluting bioresorbable vascular scaffold and the cobalt-chromium XIENCE V stent in a porcine coronary artery model. Circ Cardiovasc Interv. 2014;7:330-42.

14. Serruys PW, Katagiri Y, Sotomi Y, Zeng Y, Chevalier B, van der Schaaf RJ, Baumbach A, Smits P, van Mieghem NM, Bartorelli A, Barragan P, Gershlick A, Kornowski R, Macaya C, Ormiston J, Hill J, Lang IM, Egred M, Fajadet J, Lesiak M, Windecker S, Byrne RA, Räber L, van Geuns RJ, Mintz GS, Onuma Y. Arterial Remodeling After Bioresorbable Scaffolds and Metallic Stents. J Am Coll Cardiol. 2017;70:60-74.

15. Trabattoni D, Fabbiocchi F, Montorsi P, Calligaris G, Galli S, Ravagnani P, De Martini S, Teruzzi G, Bartorelli AL. Angiographic patterns of in-stent restenosis in men and women. Ital Heart J. 2005;6:138-42.

16. Stolker JM, Kennedy KF, Lindsey JB, Marso SP, Pencina MJ, Cutlip DE, Mauri L, Kleiman NS, Cohen DJ; EVENT Investigators. Predicting restenosis of drug-eluting stents placed in real-world clinical practice: derivation and validation of a risk model from the EVENT registry. Circ Cardiovasc Interv. 2010;3:327-34.

17. Semeraro O, Agostoni P, Verheye S, Van Langenhove G, Van den Heuvel P, Convens C, Van den Branden F, Bruining N, Vermeersch P; Reduction of
Restenosis in Saphenous Vein Grafts with Cypher Stent Trial Investigators. Re-examining minimal luminal diameter relocation and quantitative coronary angiography--intravascular ultrasound correlations in stented saphenous vein grafts: methodological insights from the randomised RRISC trial. EuroIntervention. 2009;4:633-40.

18. van Ditzhuijzen NS, Karanasos A, Bruining N, van den Heuvel M, Sorop O, Ligthart J, Witberg K, Garcia-Garcia HM, Zijlstra F, Duncker DJ, van Beusekom HM, Regar E. The impact of Fourier-Domain optical coherence tomography catheter induced motion artefacts on quantitative measurements of a PLLA-based bioresorbable scaffold. Int J Cardiovasc Imaging. 2014;30: 1013-26.

\section{Supplementary data}

Supplementary Appendix 1. Methods.

Supplementary Appendix 2. Results.

Supplementary Figure 1. Cumulative frequency distribution curves of longitudinal MLA shift from post procedure to threeyear follow-up (serial analysis of 366 lesions).

Supplementary Figure 2. Retrospective matching and serial changes (three-year, post procedure, pre procedure) of lumen, plaque, and vessel area at the three-year MLA site in lesions with acute or late relocation.

Supplementary Table 1. Baseline clinical, lesion and procedural characteristics with complete set of IVUS pre procedure, post procedure, and at three years.

Supplementary Table 2. Univariate analyses predicting late MLA relocation.

Supplementary Table 3. Clinical outcome (three-year) comparison between lesions with and without late MLA relocation.

\section{The supplementary data are published online at: https://eurointervention.pcronline.com/ doi/10.4244/EIJ-D-18-00422}




\section{Supplementary data}

\section{Supplementary Appendix 1. Methods}

\section{Definitions of indices ${ }^{14}$}

Expected balloon-artery ratio was defined as (maximal expected diameter of the device/postdilatation balloon throughout procedure) / (reference lumen diameter by IVUS derived from the average of $5 \mathrm{~mm}$ segments proximal and distal to the device segment). Expansion index was calculated as the ratio of minimum scaffold/stent area (MSA) to the average lumen area of the $5 \mathrm{~mm}$ segments proximal and distal to the device. Expansion index $<0.8$ was defined as underexpansion. Asymmetry index was calculated per lesion as $[1-($ minimum device diameter) / (maximum device diameter)] throughout an entire pullback. A lesion was characterised as asymmetric when the value of asymmetry index was $>0.3$. Eccentricity index was calculated as the ratio of the projected minimal to maximal scaffold/stent diameter at each cross-section. A scaffold/stent cross-section with the lowest eccentricity index value was used for the analysis. A scaffold/stent with eccentricity index $<0.7$ was defined as eccentric.

\section{Region of interest in preprocedural IVUS-VH analysis}

The preprocedural target ("to-be-scaffolded/stented") segments were defined by coregistration with post-procedural IVUS using identical landmarks, such as side branches, bifurcations, large calcifications, and the edge of the stent. Preprocedural IVUS-VH analysis was performed within the defined target segments ${ }^{8}$. Tissue compositions (fibrous, fibro-fatty, necrotic core, dense calcium) were expressed in area and percentages, averaged for multiple plaque-media cross-sectional areas ${ }^{9}$. Tissue compositions at the preprocedural site corresponding to the post-procedural MLA were also analysed. 


\section{Statistical analysis}

Categorical variables are presented as counts and percentages. Continuous variables are presented as mean $\pm \mathrm{SD}$ or median (interquartile range), as appropriate. Categorical variables were compared using chi-square statistics or Fisher's exact test. Continuous variables between the two groups were compared using the Student's t-test or Mann-Whitney U test, as appropriate. Overall significance of changes at three time points was analysed with repeated measures ANOVA. Paired comparisons were adjusted by the Bonferroni method. A p-value $<0.05$ was considered statistically significant. To elucidate predictors for MLA relocation, univariate analyses with logistic regression were performed first. Factors with a p-value $<0.20$ were further incorporated into a multivariate logistic regression model. In case of TLR, the IVUS documentation prior to the treatment was carried forward and included in the 3year results. Statistical analyses were performed with SPSS, Version 24.0.0.1 (IBM Corp., Armonk, NY, USA).

\section{Supplementary Appendix 2. Results}

\section{Backward matching pre and post procedure of the 3-year MLA}

Serial changes of lumen, plaque, and vessel area at the 3-year MLA site are shown in Supplementary Figure 2. When lesions with any MLA relocation (lines E, F, and G in Figure 3) were combined, both BRS and EES showed significant lumen reduction due to plaque increase and constrictive remodelling at the 3-year MLA site from post procedure to 3 years (Supplementary Figure 2A).

In lesions without acute but with late MLA relocation (line E in Figure 3 and Supplementary Figure 2B), the lumen area significantly decreased with "plaque growth" and constrictive remodelling in both arms from post procedure to 3 years. In lesions with 
acute, but without late MLA relocation (line F in Figure 3 and Supplementary Figure 2C), BRS showed significant lumen area decrease with non-significant "plaque growth" and significant constrictive remodelling; EES showed lumen area decrease with non-significant "plaque growth" and stable vessel area from post procedure to 3 years. In lesions with acute and late relocation, BRS showed significant lumen narrowing with significant "plaque growth" and stable vessel area whereas EES showed significant lumen narrowing with nonsignificant "plaque growth" and constrictive remodelling (line G in Figure 3 and Supplementary Figure 2D). 


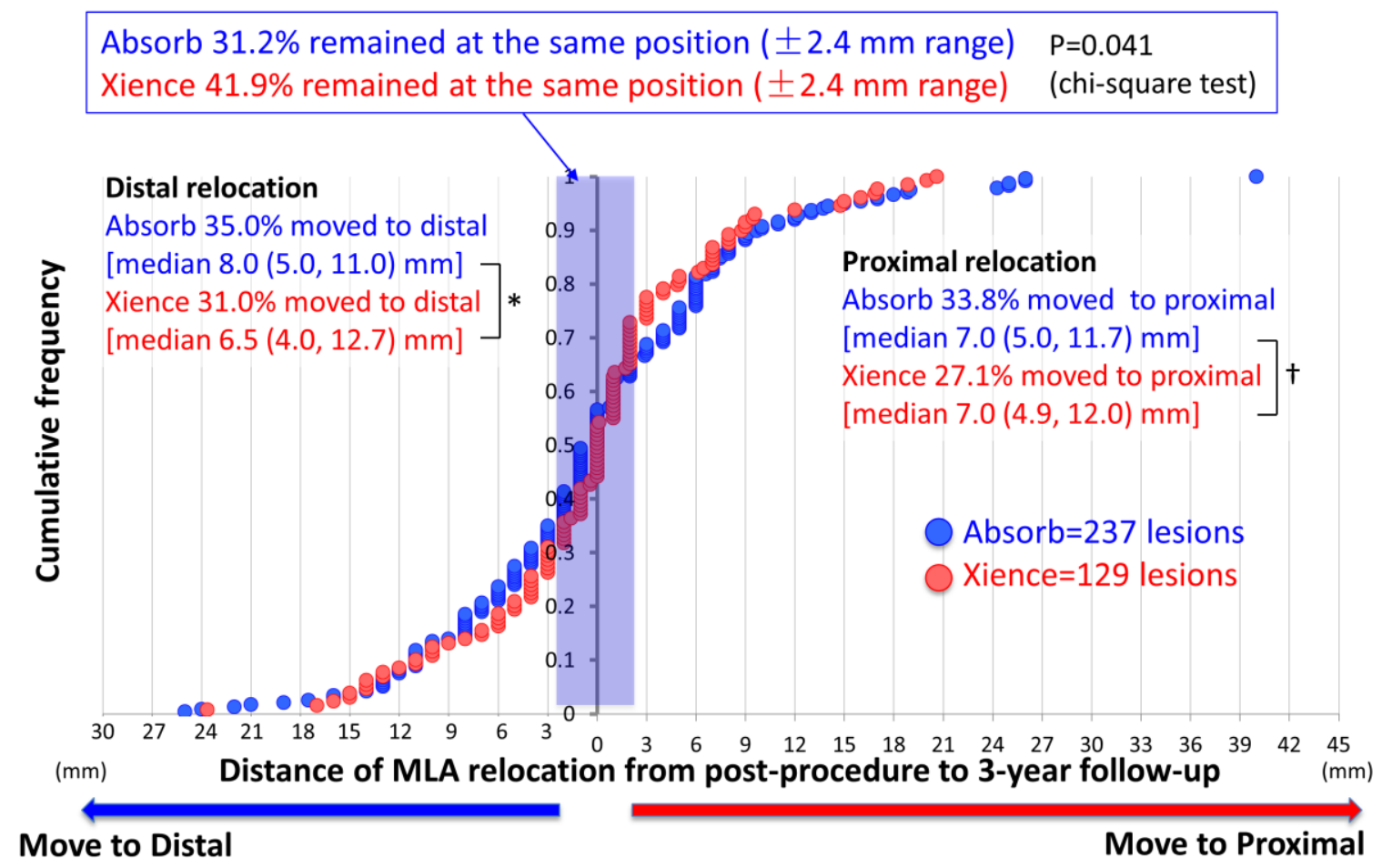

Supplementary Figure 1. Cumulative frequency distribution curves of longitudinal MLA shift from post procedure to three-year follow-up (serial analysis of 366 lesions).

Blue column indicates the range without relocation, taking into account axial movement of the IVUS probe during the cardiac cycle ${ }^{10}$. ${ }^{*} \mathrm{p}=0.580, \dagger \mathrm{p}=0.973$ (Mann-Whitney U test).

MLA: minimum lumen area 


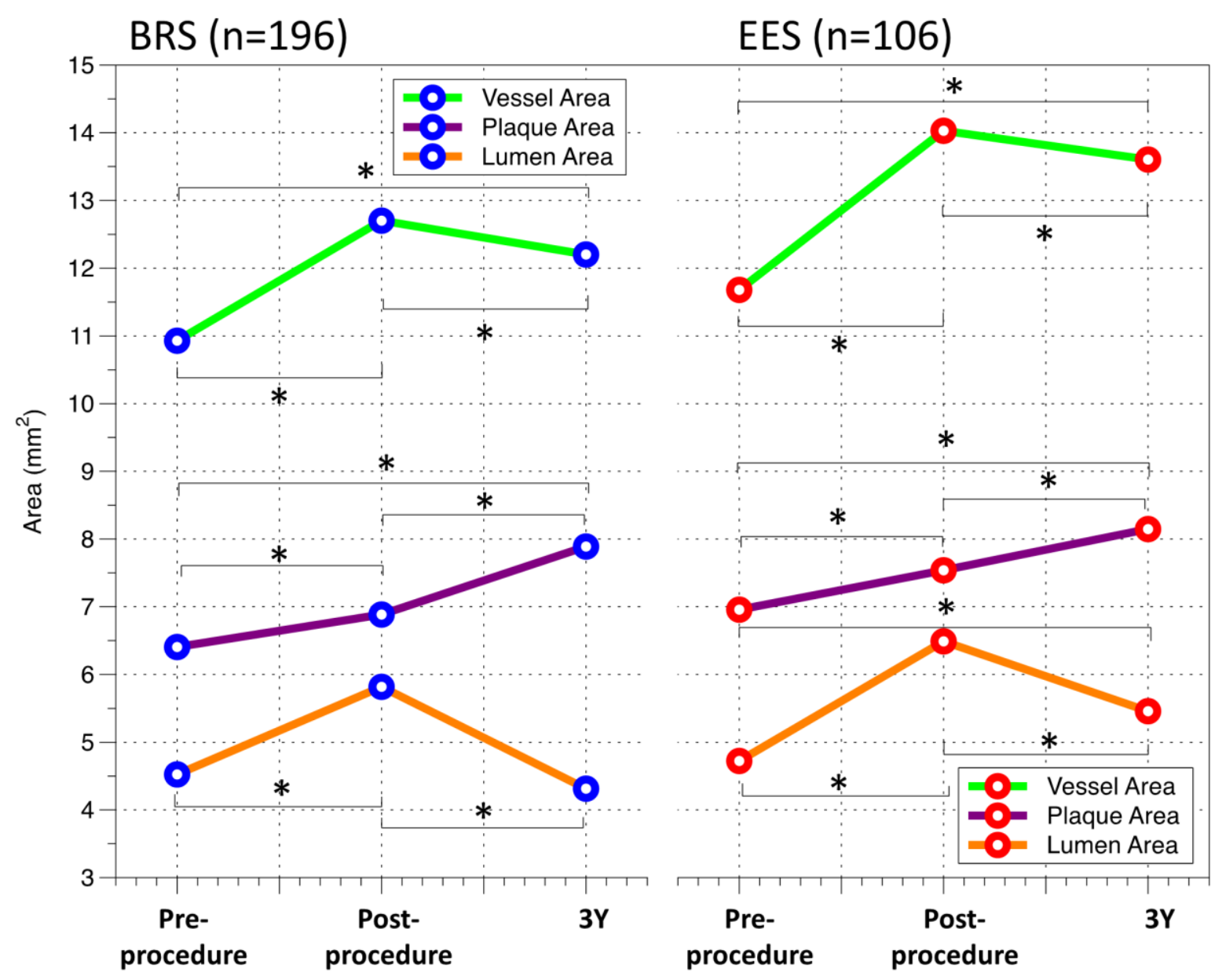




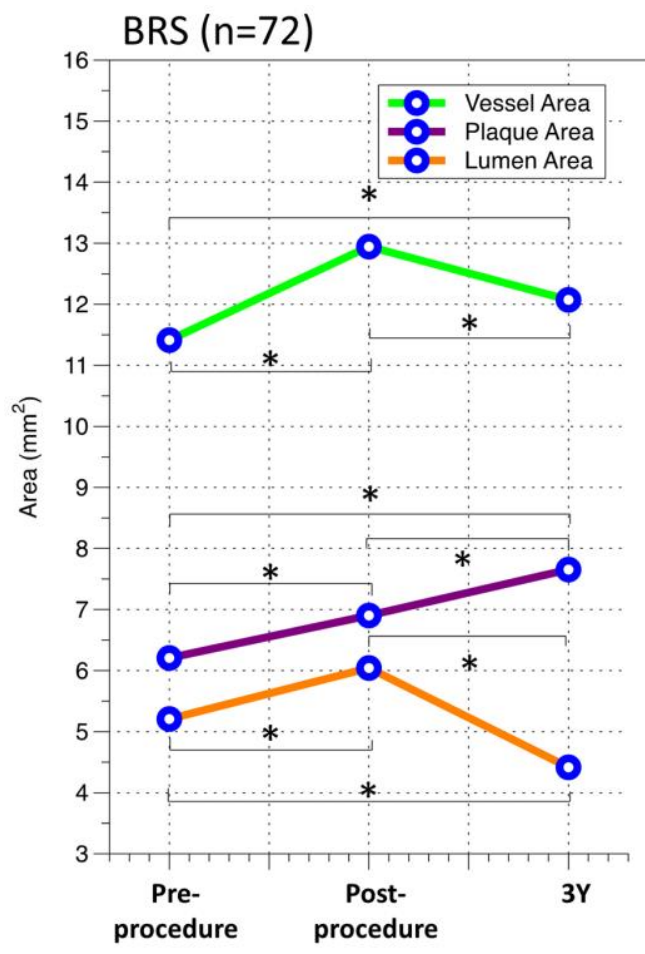

C

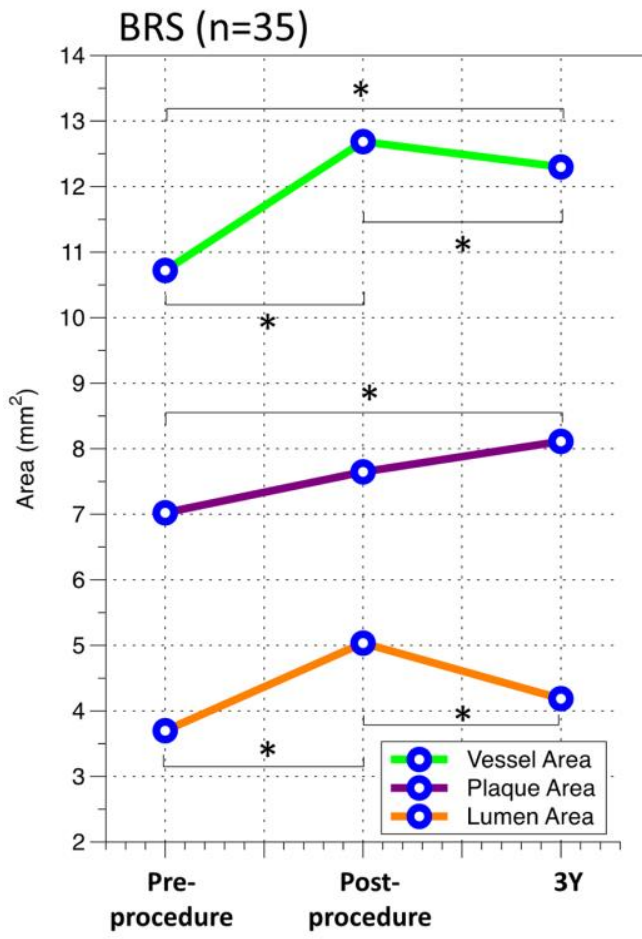

C

\section{$\operatorname{EES}(n=34)$}
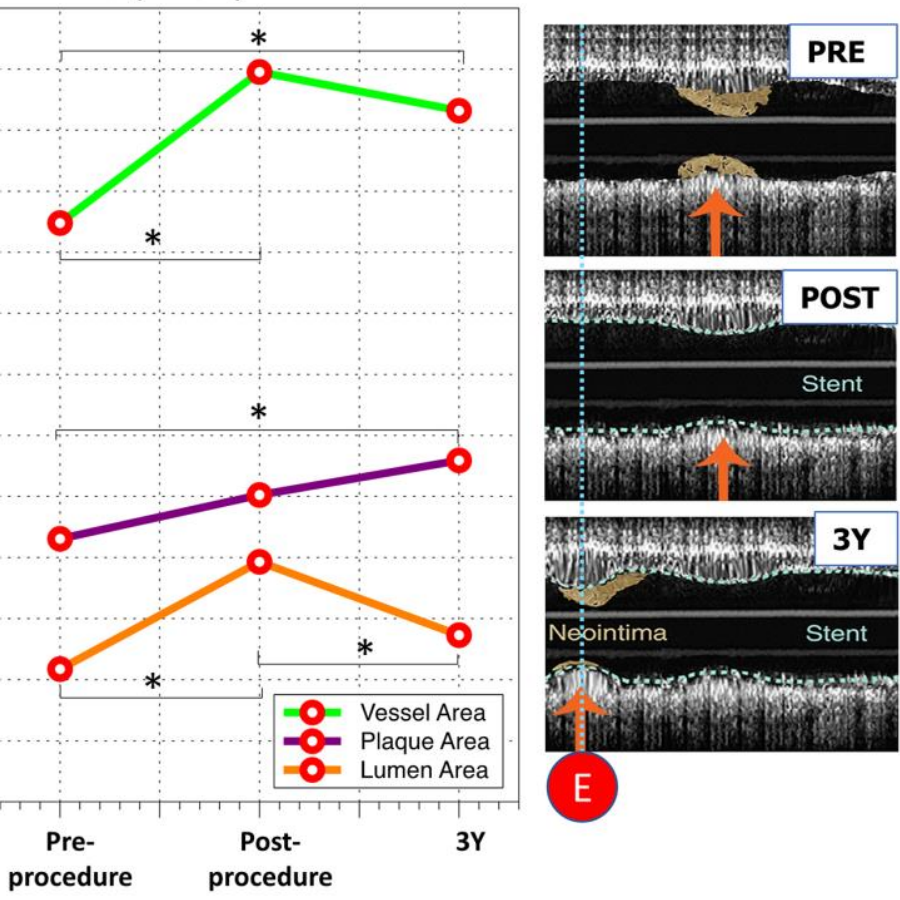

procedure procedure
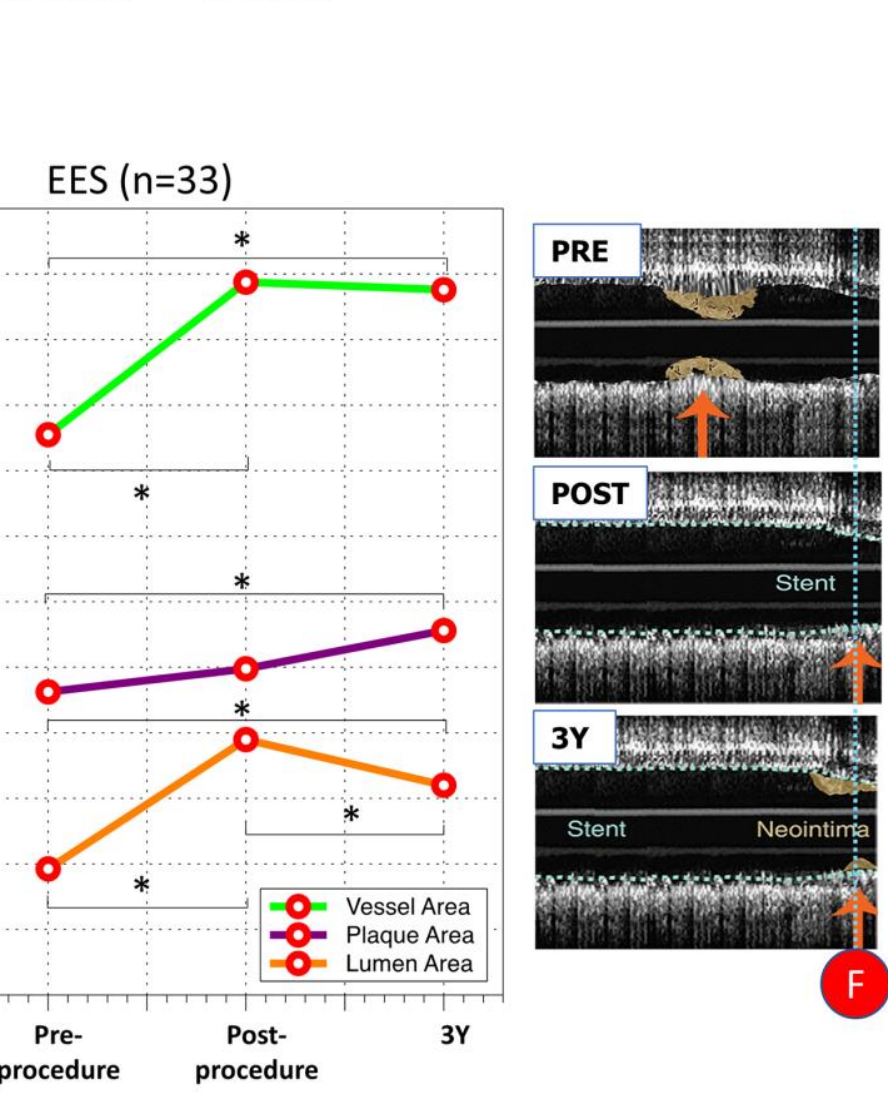

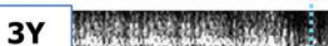

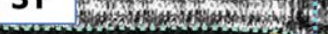

Stent

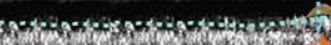

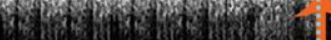




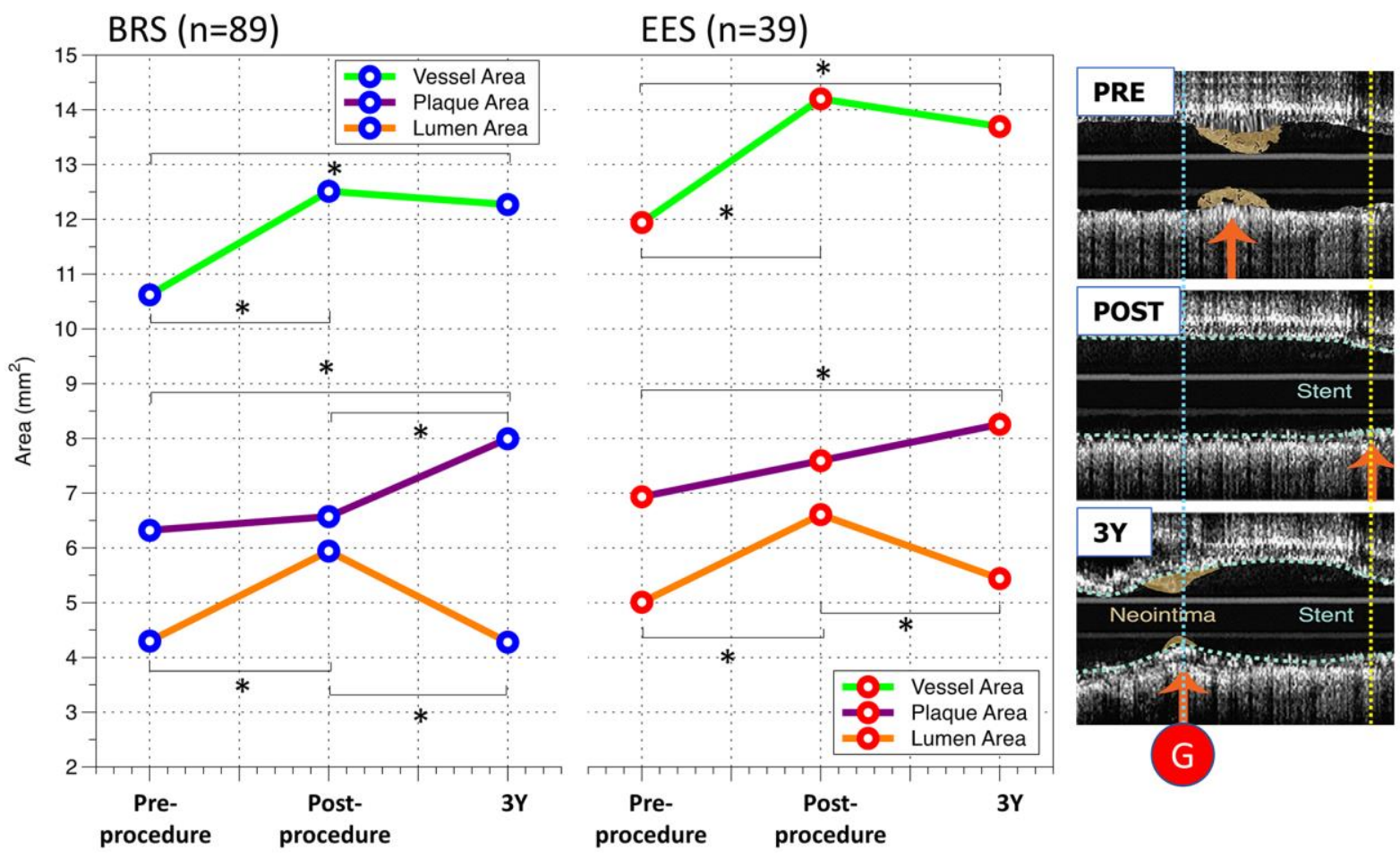

Supplementary Figure 2. Retrospective matching and serial changes (three-year, postprocedure, pre-procedure) of lumen, plaque, and vessel area at the three-year MLA site in lesions with acute or late relocation.

A) Serial changes at the 3-year MLA site in lesions with any (acute or late) MLA relocation. Aggregated data from lines E, F, and G in Figure 3.

B) Serial changes at the 3-year MLA site in lesions without acute relocation but with late relocation. Line E in Figure 3.

C) At the site of 3-year MLA in lesions with acute but without late MLA relocation. Line F in Figure 3.

D) At the site of 3-year MLA in lesions with acute and late relocation. Line G in Figure 3. All serial changes were significant in ANOVA for repeated measurement. P-values for pairwise comparisons were adjusted by Bonferroni correction. ${ }^{*} \mathrm{p}<0.05$.

BRS: bioresorbable scaffold; EES: everolimus-eluting stent 
Supplementary Table 1. Baseline clinical, lesion and procedural characteristics with complete set of IVUS pre procedure, post procedure, and at three years.

\begin{tabular}{|c|c|c|c|}
\hline & BRS & EES & $p$-value \\
\hline Patient characteristics & $n=224$ & $\mathrm{n}=120$ & \\
\hline Age (years) & $61 \pm 10$ & $60 \pm 9$ & 0.321 \\
\hline Male & $163(72.8)$ & $98(81.7)$ & 0.066 \\
\hline Current smoking & $58(25.9)$ & $27(22.5)$ & 0.487 \\
\hline Hypertension requiring medication & $142(63.4)$ & $77(64.2)$ & 0.887 \\
\hline Dyslipidaemia requiring medication & $158(70.5)$ & $87(72.5)$ & 0.701 \\
\hline Diabetes & $46(20.5)$ & $28(23.3)$ & 0.547 \\
\hline Unstable angina & $41(18.3)$ & $26(21.7)$ & 0.453 \\
\hline Prior MI & $60(26.9)$ & $34(28.3)$ & 0.777 \\
\hline Previous PCI & $71(31.7)$ & $40(33.3)$ & 0.757 \\
\hline Serum creatinine $(\mu \mathrm{mol} / \mathrm{L})$ & $80.9 \pm 18.1$ & $82.5 \pm 19.5$ & 0.467 \\
\hline Obesity $\left(\mathrm{BMI} \geq 30 \mathrm{~kg} / \mathrm{m}^{2}\right)$ & $58(25.9)$ & $34(28.3)$ & 0.626 \\
\hline Lesions & 237 lesions & 129 lesions & \\
\hline Lesion location & & & 0.340 \\
\hline Right coronary artery & $62(26.2)$ & $40(31.0)$ & \\
\hline Left anterior descending & $110(46.4)$ & $62(48.1)$ & \\
\hline Left circumflex artery & $65(27.4)$ & $27(20.9)$ & \\
\hline Lesion classification & & & 0.301 \\
\hline A & $3(1.3)$ & $0(0.0)$ & \\
\hline B1 & $136(57.4)$ & $69(53.5)$ & \\
\hline $\mathrm{B} 2$ & $96(40.5)$ & $60(46.5)$ & \\
\hline $\mathrm{C}$ & $2(0.8)$ & $0(0.0)$ & \\
\hline
\end{tabular}




\section{Procedural details}

Predilatation performed

Nominal diameter of predilatation balloon $(\mathrm{mm})$

Maximal pressure during predilatation (atm)

Nominal diameter of device (mm)

Length of implanted device (mm)

Maximal pressure during device

implantation (atm)

Expected device diameter (mm)

Post-dilatation performed

Nominal diameter of post-dilatation

balloon $(\mathrm{mm})$

Maximal pressure during post-dilatation (atm)

Expected diameter of post-

dilatation/device balloon throughout procedure $(\mathrm{mm})$

Expected balloon-artery ratio

\section{Post-procedural patient-related factors}

Mean LDL cholesterol (mmol/L)

$$
\begin{array}{ll}
n=237 & n=129 \\
\text { lesions } & \text { lesions }
\end{array}
$$

$237(100.0) \quad 127(98.4) \quad 0.055$

$2.61 \pm 0.37 \quad 2.65 \pm 0.36 \quad 0.309$

$12.13 \pm 3.02 \quad 12.33 \pm 3.05 \quad 0.540$

$\begin{array}{lll}3.02 \pm 0.31 & 3.07 \pm 0.28 & 0.161\end{array}$

$23.43 \pm 10.41 \quad 23.37 \pm 8.96 \quad 0.954$

$13.22 \pm 2.73 \quad 13.91 \pm 2.61 \quad 0.018$

$\begin{array}{lll}3.34 \pm 0.34 & 3.29 \pm 0.34 & 0.179\end{array}$

$144(60.8)-78(60.5) \quad 0.956$

$\begin{array}{lll}3.16 \pm 0.33 & 3.28 \pm 0.37 & 0.018\end{array}$

$15.20 \pm 3.04 \quad 16.78 \pm 3.37<0.001$

$\begin{array}{lll}3.38 \pm 0.34 & 3.38 \pm 0.36 & 0.970\end{array}$

$\begin{array}{lll}1.20 \pm 0.15 & 1.17 \pm 0.16 & 0.161\end{array}$

$2.33 \pm 0.64 \quad 2.28 \pm 0.59$

0.483 
Supplementary Table 2. Univariate analyses predicting late MLA relocation.

OR $[95 \% \mathrm{CI}] \quad p$-value

\section{Patient-related factors}

Age (per year)

$1.00[0.98,1.02] \quad 0.995$

Female

$1.87[1.09,3.22] \quad 0.024$

Current smoker

$0.90[0.55,1.46] \quad 0.661$

Hypertension requiring medication

$1.31[0.85,2.03] \quad 0.220$

Dyslipidaemia requiring medication

$0.76[0.47,1.23]$

0.267

Any diabetes

$0.90[0.54,1.51]$

0.691

Prior MI

$1.07[0.67,1.72]$

0.778

Previous PCI

1.50 [0.94, 2.39]

0.088

Family history of CAD

0.89 [0.57, 1.39]

0.602

Unstable angina

$0.83[0.49,1.40]$

0.490

BMI $>30\left(\mathrm{~kg} / \mathrm{m}^{2}\right)$

$0.90[0.56,1.45]$

0.674

\section{IVUS post procedure}

IVUS: mean vessel area (per $\mathrm{mm}^{2}$ )

$\begin{array}{ll}1.00[0.94,1.06] & 0.905 \\ 1.01[0.88,1.16] & 0.922 \\ 0.99[0.90,1.08] & 0.809 \\ 0.98[0.95,1.01] & 0.248\end{array}$

IVUS: mean lumen area (per $\mathrm{mm}^{2}$ )

IVUS: mean plaque area (per $\mathrm{mm}^{2}$ )

$0.98[0.95,1.01]$

0.248

IVUS: mean plaque burden (per \%)

Tissue composition by IVUS-VH (in-device segment)

Fibrous (per $\mathrm{mm}^{2}$ )

$0.93[0.69,1.24] \quad 0.602$

Fibro-fatty (per $\mathrm{mm}^{2}$ )

$1.02[0.88,1.17]$

0.832

Dense calcium (per $\mathrm{mm}^{2}$ )

$1.58[0.46,5.47]$

0.470

Necrotic core (per $\mathrm{mm}^{2}$ )

$1.17[0.66,2.08]$

0.586

Fibrous (per \%)

0.99 [0.97, 1.01]

0.440

Fibro-fatty (per \%)

$1.00[0.99,1.01]$

0.980

Dense calcium (per \%)

1.02 [0.97, 1.07]

0.483

Necrotic core (per \%)

$1.02[0.98,1.05]$

0.358

Necrotic core $>16.7 \%$

$1.02[0.66,1.59]$

0.915

Tissue composition by IVUS-VH at the cross-

section matched with post-procedural MLA

Fibrous (per $\mathrm{mm}^{2}$ )

$0.96[0.76,1.20]$

0.709 
Fibro-fatty (per $\mathrm{mm}^{2}$ )

1.01 [0.92, 1.11]

0.839

Dense calcium (per $\mathrm{mm}^{2}$ )

$1.17[0.61,2.24] \quad 0.638$

Necrotic core (per $\mathrm{mm}^{2}$ )

$1.07[0.74,1.55]$

0.702

Fibrous (per \%)

$1.00[0.98,1.01]$

0.632

Fibro-fatty (per \%)

$0.99[0.98,1.00]$

0.283

Dense calcium (per \%)

$1.01[0.98,1.04]$

0.470

Necrotic core (per \%)

$1.01[0.99,1.03]$

0.414

Necrotic core $>16.7 \%$

$1.00[0.64,1.55]$

0.989

\section{Procedural factors}

Nominal diameter of predilatation balloon (per
$\mathrm{mm})$
Maximal pressure during predilatation (per
atm)
BRS implantation
Nominal diameter of device (per $\mathrm{mm}$ )
Length of implanted device (per $\mathrm{mm}$ )
Maximal pressure during device implantation

$0.99[0.55,1.77]$

0.961

$1.02[0.95,1.10]$

0.532

$1.56[1.01,2.41]$

0.047

$1.08[0.53,2.20]$

0.824

$1.04[1.01,1.06]$

0.007 (per atm)

$1.02[0.95,1.11]$

0.547

Expected diameter of device balloon (per mm)

$1.32[0.70,2.47]$

0.394

Post-dilatation performed

$1.04[0.67,1.60]$

0.869

Nominal diameter of post-dilatation balloon (per mm)

$0.71[0.33,1.56] \quad 0.396$

Maximal pressure at either device implantation or post-dilatation (per atm)

$1.07[0.99,1.15] \quad 0.072$

Expected diameter of post-dilatation balloon (per mm)

$0.82[0.38,1.78]$

0.616

Maximal expected diameter of balloon throughout procedure (per mm)

$1.12[0.61,2.07] \quad 0.717$

Expected balloon-artery ratio (per 0.1)

$0.99[0.85,1.14] \quad 0.864$

Expected balloon-artery ratio $>1.25$

$1.08[0.67,1.75]$

0.758

Post-procedural performance index by IVUS

Expansion index (per 0.1)

$1.07[0.91,1.25] \quad 0.400$

Expansion index $<0.8$

$0.76[0.46,1.27]$

0.292 
Asymmetry index (per 0.1)

$1.13[0.86,1.48] \quad 0.372$

Asymmetry index $>0.3$

$1.38[0.90,2.11] \quad 0.139$

Minimum eccentricity index (per 0.1)

$0.80[0.60,1.07] \quad 0.126$

Minimum eccentricity index $<0.7$

$1.62[0.92,2.87] \quad 0.097$

\section{Post-procedural patient factors}

Mean LDL (per mmol/L)

$1.30[0.91,1.85] \quad 0.148$

DAPT continuation

$1.22[0.72,2.04] \quad 0.459$

ACE inhibitor/ARB continuation

$0.99[0.64,1.53]$

0.958

Statin continuation

$0.80[0.52,1.23]$

0.311 
Supplementary Table 3. Clinical outcome (three years) comparison between lesions with and without late MLA relocation.

\begin{tabular}{|c|c|c|c|c|c|c|c|c|c|c|c|c|c|c|c|}
\hline & \multicolumn{5}{|c|}{ Overall } & \multicolumn{5}{|c|}{ Absorb } & \multicolumn{5}{|c|}{ XIENCE } \\
\hline & \multicolumn{2}{|c|}{$\begin{array}{l}\text { Relocation } \\
(\mathrm{n}=238)\end{array}$} & \multicolumn{2}{|c|}{$\begin{array}{c}\text { No relocation } \\
(\mathrm{n}=128)\end{array}$} & $\begin{array}{c}p- \\
\text { value }\end{array}$ & \multicolumn{2}{|c|}{$\begin{array}{c}\text { Relocation } \\
(\mathrm{n}=163)\end{array}$} & \multicolumn{2}{|c|}{$\begin{array}{c}\text { No relocation } \\
(\mathrm{n}=74)\end{array}$} & $\begin{array}{c}p- \\
\text { value }\end{array}$ & \multicolumn{2}{|c|}{$\begin{array}{c}\text { Relocation } \\
(\mathrm{n}=75)\end{array}$} & \multicolumn{2}{|c|}{$\begin{array}{c}\text { No relocation } \\
(\mathrm{n}=54)\end{array}$} & $\begin{array}{c}p- \\
\text { value }\end{array}$ \\
\hline POCE & 45 & $18.9 \%$ & 22 & $17.2 \%$ & 0.777 & 23 & $14.1 \%$ & 13 & $17.6 \%$ & 0.559 & 22 & $29.3 \%$ & 9 & $16.7 \%$ & 0.143 \\
\hline $\begin{array}{c}\text { Cardiac } \\
\text { death }\end{array}$ & 0 & $0.0 \%$ & 0 & $0.0 \%$ & NA & 0 & $0.0 \%$ & 0 & $0.0 \%$ & NA & 0 & $0.0 \%$ & 0 & $0.0 \%$ & NA \\
\hline TV-MI & 7 & $2.9 \%$ & 4 & $3.1 \%$ & 1.000 & 5 & $3.1 \%$ & 4 & $5.4 \%$ & 0.466 & 2 & $2.7 \%$ & 0 & $0.0 \%$ & 0.509 \\
\hline Any TLR & 13 & $5.5 \%$ & 4 & $3.1 \%$ & 0.437 & 8 & $4.9 \%$ & 2 & $2.7 \%$ & 0.728 & 5 & $6.7 \%$ & 2 & $3.7 \%$ & 0.698 \\
\hline Late ST & 1 & $0.4 \%$ & 0 & $0.0 \%$ & 1.000 & 1 & $0.6 \%$ & 0 & $0.0 \%$ & 1.000 & 0 & $0.0 \%$ & 0 & $0.0 \%$ & NA \\
\hline VLST & 0 & $0.0 \%$ & 0 & $0.0 \%$ & $\mathrm{NA}$ & 0 & $0.0 \%$ & 0 & $0.0 \%$ & NA & 0 & $0.0 \%$ & 0 & $0.0 \%$ & NA \\
\hline
\end{tabular}

ST was defined as definite or probable ST according to ARC definition.

CI: clinically indicated; DOCE: device-oriented composite endpoint (cardiac death, target vessel myocardial infarction, or clinically indicated target lesion revascularisation); POCE: patient-oriented composite endpoint (all death, all myocardial infarction, or all revascularisation); ST: stent thrombosis; TLR: target lesion revascularisation; TV-MI: target vessel myocardial infarction; VLST: very late stent thrombosis 